\title{
A Case Control Study of Subjective Quality of Life in Outpatients with Depression
}

\author{
Francis John Davou1 ${ }^{*}$, Moses David Audu1 ${ }^{1}$ Akinwande 0. Akinhanmi², Musa Usman Umar', \\ Tungchama Friday Philip"1, Maigari Yusufu Taru'1, Aishatu Armiya'u Yushau4
}

\author{
${ }^{1}$ Department of Psychiatry, University of Jos, Jos, Nigeria \\ ${ }^{2}$ Federal Neuro-Psychiatric Hospital, Aro, Abeokuta, Nigeria \\ ${ }^{3}$ Bayero University Kano/Aminu Kano Teaching Hospital, Kano, Nigeria \\ ${ }^{4}$ Jos University Teaching Hospital, Jos, Nigeria \\ Email: *davoufj@yahoo.com
}

How to cite this paper: Davou, F.J., Audu, M.D., Akinhanmi, A.O., Umar, M.U., Philip, T.F., Taru, M.Y. and Yushau, A.A. (2017) A Case Control Study of Subjective Quality of Life in Outpatients with Depression. Open Journal of Psychiatry, 7, 248260.

https://doi.org/10.4236/ojpsych.2017.74022

Received: March 30, 2017

Accepted: August 13, 2017

Published: August 16, 2017

Copyright (c) 2017 by authors and Scientific Research Publishing Inc. This work is licensed under the Creative Commons Attribution International License (CC BY 4.0).

http://creativecommons.org/licenses/by/4.0/ (c) (i) Open Access

\begin{abstract}
Background: Depression is one of the leading causes of disability including impairment in the subjective Quality of Life (QOL) of the patient. Unfortunately, only a fraction receives the correct diagnosis and treatment in general practice. This study aims to determine the subjective Quality of Life of depressed patients. Method: A representative sample of adults, 18 years and above (100 each for cases and controls), were assessed for QOL using the World Health Organization Quality of Life instrument (WHOQOL-BREF). Respondents were also evaluated for socio-demographic factors. Major depressive disorder was assessed using the Mini International Neuropsychiatric Interview. Severity of depression was measured using Hamilton's Rating Scale for Depression and global functioning was assessed with the Global Assessment of Functioning scale. Results: Majority of the participants were females (62.0\%) and young with a mean age of $39.11 \pm 12.40$ years. Overall subjective QOL $(P<0.033)$, as well as the physical $(P<0.002)$, psychological $(P<0.001)$, social $(P<0.006)$ and environmental $(P<0.048)$ domains were significantly impaired in depressed patients compared to healthy control. Global functioning was also impaired $(P<0.001)$ in depressed patients compared to healthy control. Conclusion: The finding of the study showed that depression is a serious illness that affects the patient's perception of the quality of his/her life. It is therefore very necessary to innovate better treatment modalities to reduce its burden.
\end{abstract}

\section{Keywords}

Depression, Quality of Life, Outpatients, Controls 


\section{Introduction}

Quality of life (QOL) is a broad ranging concept, incorporating in a complex way the person's physical health, psychological state, level of independence, social relationships, personal beliefs and relationship to salient features in the environment [1].

The World Health Organization (WHO) has described quality of life as individuals' perception of their position in life in the context of the culture and value systems in which they live and in relation to their goals, expectations, standards and concerns [2]. With this in mind, it would be right to say that QOL is largely dependent on several factors including economic, political, social, health related factors, etc.

Depressive disorders are highly prevalent and are associated with functional, psychological and occupational impairment. The prevalence of major depressive disorder over the course of a life time is estimated to range between $6 \%-17 \%$ [3]. An estimate within the community and in primary care elevates these percentages to $10 \%-30 \%$ of the population [3] [4]. Depression is presently considered to be the fourth $\left(4^{\text {th }}\right)$ leading cause of disability [5] and is projected to become the second $\left(2^{\text {nd }}\right)$ leading cause of disability by 2020 [6].

In current literature, there are several studies that demonstrate the association of depression with quality of life measures. Depressed patients suffer diminished quality of life equal to or greater than those with other chronic conditions and depression has also been associated with a decrease in experiencing positive well-being, impairment in role functioning and disabilities in social functioning [7] [8] [9]. Patients with depressive disorders have been found to have poorer subjective quality of life than healthy control subjects [10] [11] [12].

Depressive disorders are common illnesses associated with relatively long duration of episodes, high rates of chronicity, relapses and recurrence [13] [14].

Several studies have examined quality of life in patients with severe depressive disorders [15] [16] [17]. Notable among these studies was that conducted by the National Institute of Mental Health (NIMH) Epidemiological Catchment Area Program [18], which showed that patients with major depressive disorders or sub-syndromal depression experienced higher levels of household strain, social irritability, financial stress, limitation in occupational functioning, poor health status and days lost from work [19] [20]. Another study also found that women with major depressive disorder had impairment in family, marital, occupational and leisure activities [21]. Depressive disorders have impacted negatively on the quality of life of patients [22]-[35]. Despite the debilitating nature of depression, about $50 \%-60 \%$ of cases remain undetected in primary care and even the patients who receive correct diagnosis are not given appropriate and specific treatment [36] [37].

The aim of this study therefore is to determine the subjective quality of life of depressed outpatients currently receiving drug treatment in comparison with socio-demographically matched controls. The study is also relevant because 
there are many studies showing that depression affects the quality of life in a negative way. Most of them are from developed nation with Caucasian population. This study records the impact of depression among Nigerian population. From that epidemiological aspect, this is a good addition to the current literature.

\section{Method and Materials}

Ethical clearance was obtained from the Joint Ethical Committee of the Jos University Teaching Hospital before the study was carried out.

The study was a case-control study conducted at the psychiatric outpatient clinic of the Jos University Teaching Hospital.

Adults (18 - 60 years) who have been diagnosed to have depression using Mini International Neuropsychiatry Interview (MINI) and have been receiving treatment for at least 6 months were included in the study as cases.

Those excluded from the cases were patients with other physical or neurological conditions, those with head injury, patients with substance use disorders and those with bipolar affective disorder in depressive phase.

\subsection{Sociodemographic Questionnaire}

Socio-demographic variables were measured using a semi-structured socio-demographic questionnaire designed by the authors. This questionnaire was administered to enquire about the following socio-demographic data; age, sex, ethnicity, marital status, religion, educational level, monthly income, occupation, level of social support received from relations. Number of depressive episodes was also included in the sociodemographic questionnaire.

\subsection{World Health Organization Quality of Life Brief}

Subjective quality of life was assessed using the World Health Organization Quality of Life Scale-Brief version (WHOQOL-BREF) which is a 26 -item self administered generic questionnaire, it is a short version of the WHOQOL-100 scale [38]. The instrument was developed to measure subjective response of patients rather than their objective life conditions, with assessment covering the preceding 2-week period. This instrument is available in a wide range of languages and has been employed in a variety of cultural settings (including subSaharan Africa like Nigeria) [35], and yields comparable scores across cultures.

\subsection{Mini International Neuropsychiatric Interview}

Depression was diagnosed with the Mini International Neuropsychiatric Interview (M.I.N.I) English version 5.0.0 [39]. The MINI is a brief structured interview designed for major axis I psychiatric disorders in DSM-IV and ICD-10. It has both life time and current diagnosis versions. The life time diagnosis version was used for this study in order to provide a premise for comparing homogenous group. 


\subsection{Data Analysis}

Data analysis was done using the Statistical Package for Social Sciences (SPSS) version 17.0. The result was presented using simple descriptive statistics.

Analysis of categorical and continuous variables was done using chi-square test and paired $t$-test respectively. Domain scores of the patients (as a group) was compared with those of the matched general population (as a group) using paired $t$-test.

Summary of scores was generated for the WHOQOL-BREF by organizing the questionnaire items into groups representing the domains covered by the questionnaire. The domain scores of the WHOQOL-BREF were calculated according to the instructor's manual and served as the dependent variable.

Statistical significance was set at $P<0.05$.

\subsection{Procedure}

Consecutive outpatient attendees who were on follow up for depressive illness at the psychiatry clinic of Jos University Teaching Hospital were identified and the Mini International Neuropsychiatric Interview (MINI) was used to confirm the diagnosis and to diagnose ongoing depression among the cases.

The control population was obtained from a cosmopolitan community in Jos, the State Capital using a multi-stage sampling method. The MINI (Mini International Neuropsychiatric Interview) questionnaire was administered to the target control population to identify and exclude those that scored high for depression.

Stage 1: Tudun Wada (which has 18 settlements) was selected from Jos North Local Government Area of Plateau state.

Stage 2: Ten settlements were selected from the original 18 settlements through balloting. Stage 3: The number of housing units (as used during the National Population Commission, National census of 2006) [40] was identified within the ten settlements.

Stage 4: All the selected enumeration areas were visited and the housing units listed (twenty housing units per settlement were listed and numbered). These lists (200 in total) were entered into a computer to generate a table of random numbers from which the study households were selected.

Stage 5: A full listing of all residents in each selected housing unit was obtained from an informant and those who fulfill the criteria for the study were identified. A participant was then selected from each housing unit until the required control sample was reached.

\section{Results}

The sociodemographic parameter of all participants (Cases and Controls) is as illustrated below.

As shown in Table 1, A total of 200 participants were recruited into the study (100 each for Cases and Controls) Females constituted the majority of participants, $64.0 \%$ for cases and $60.0 \%$ for controls compared to the males. 
Table 1. Socio-demographic characteristics of respondents.

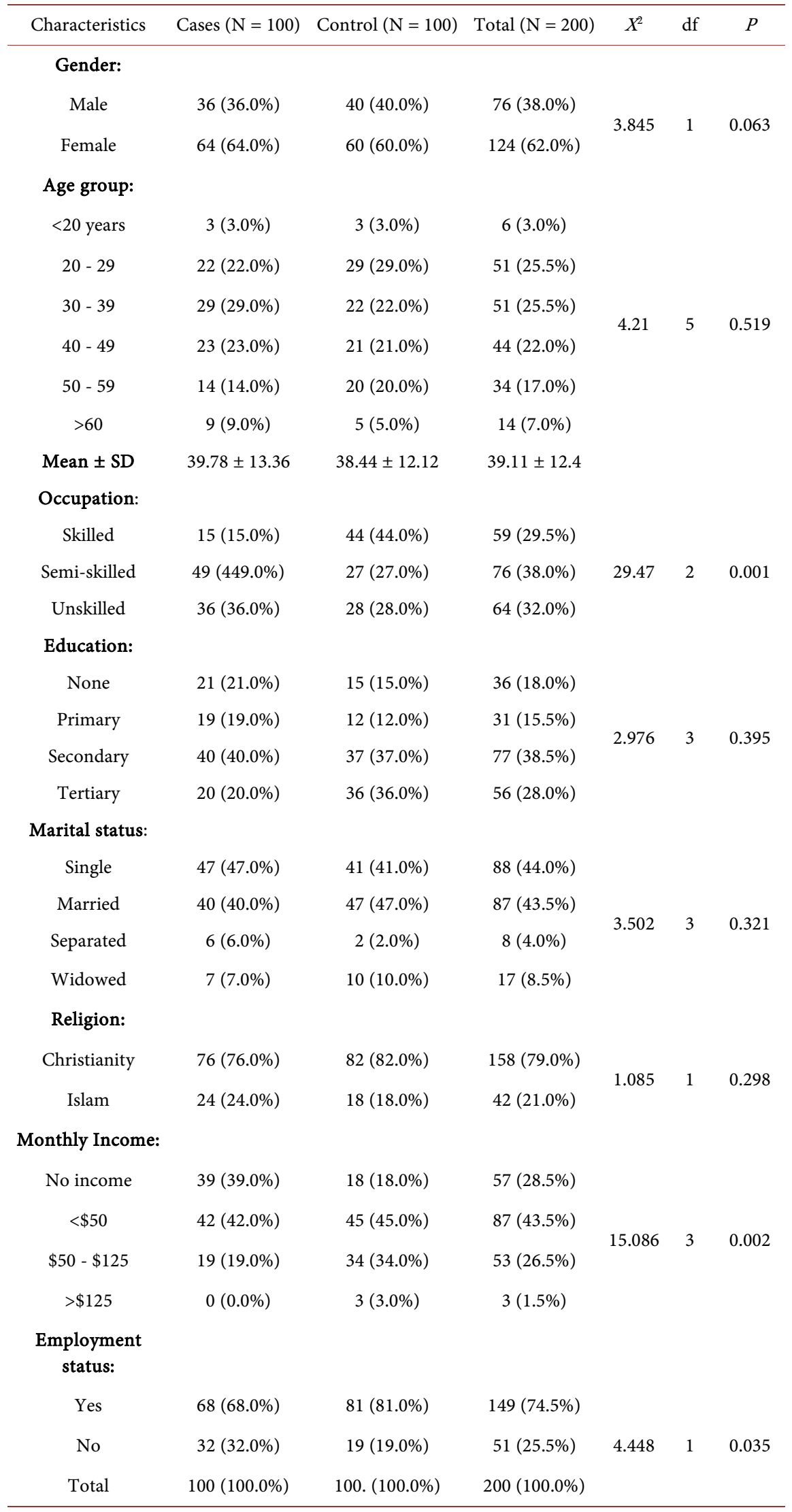


The mean age \pm SD of the cases was $39.78 \pm 13.36$ years while that of the controls was $38.44 \pm 12.12$ years.

Of the participants, 158 (79.0\%) were Christians and 42 (21.0\%) were Muslims.

A sizeable number of the participants were single 88 (44.0\%) and married 87 (43.5\%). Only 8 (4.0\%) were separated and 17 (8.5\%) were widowed.

Thirty six (18.0\%) of the respondents had no formal education, 31 (15.5\%) had acquired primary education while $77(38.5 \%)$ and $56(28.0 \%)$ had secondary and tertiary education respectively.

Most of the participants studied were employed 149 (74.5\%) while 51 (25.5\%) were not. Among the controls, $81.0 \%$ were employed while $19.0 \%$ had no work. The category of occupation $(P<0.001)$, monthly income $(P<0.002)$ and employment status $(P<0.035)$ were all statistically significant.

A statistically significant relationship $(P<0.002)$ was found to exist between cases and controls with regards to overall quality of life as presented on Table 2.

As shown in Table 3, the number of depressive episodes on overall quality of life was not statistically significant $(P=0.822)$.

The mean domain scores were higher for the controls in comparison with the cases. An association was observed between participants with regards to depressive disorders. See Table 4.

Table 2. Comparison of overall quality of life between cases and controls.

\begin{tabular}{cccccc}
\hline WHOQOL Overall Scores & Cases $(100)$ & Controls $(\mathrm{N}=100)$ & $X^{2}$ & df & $P$ \\
\hline Poor & $22(22.0 \%)$ & $17(17.0 \%)$ & & & \\
Neutral & $18(18.0 \%)$ & $4(4.0 \%)$ & 12.147 & 2 & 0.002 \\
Good & $0(60.0 \%)$ & $79(79.0 \%)$ & & & \\
\hline
\end{tabular}

Table 3. Relationship between overall quality of life and number of depressive episodes among cases.

\begin{tabular}{|c|c|c|c|c|c|}
\hline \multirow{2}{*}{ WHOQOL Overall Scores } & \multicolumn{2}{|c|}{ Number of episodes } & \multirow{2}{*}{$X^{2}$} & \multirow{2}{*}{$\mathrm{df}$} & \multirow{2}{*}{$P$} \\
\hline & Once & >once & & & \\
\hline Poor $(\mathrm{N}=39)$ & $16(37.2 \%)$ & $23(40.4 \%)$ & & & \\
\hline Neutral $(\mathrm{N}=16)$ & $8(18.6 \%)$ & $8(14.0 \%)$ & 0.393 & 2 & 0.822 \\
\hline Good $(\mathrm{N}=45)$ & $19(44.2 \%)$ & $26(45.6 \%)$ & & & \\
\hline
\end{tabular}

Table 4. Mean domain scores of cases and controls.

\begin{tabular}{ccccc}
\hline WHOQOL Domain & Cases (100) & Controls (100) & $t$-test & $P$ \\
\hline Overall QoL & $3.72 \pm 1.22$ & $4.00 \pm 1.08$ & 2.148 & 0.033 \\
Domain 1 (Physical) & $15.06 \pm 3.57$ & $16.29 \pm 2.77$ & 6.46 & 0.002 \\
Domain2 (Psychological) & $11.99 \pm 2.73$ & $14.04 \pm 2.90$ & 7.74 & 0.001 \\
Domain 3 (Social) & $14.46 \pm 3.83$ & $15.06 \pm 3.21$ & 3.27 & 0.006 \\
Domain 4 (Environmental) & $14.68 \pm 2.51$ & $16.34 \pm 2.85$ & 2.55 & 0.048 \\
\hline
\end{tabular}

Values are expressed as Mean \pm SD. 


\section{Discussion}

\subsection{Sociodemographic Characteristics of Participants}

Out of the 200 participants studied $62 \%$ were females. This female predominance applies to both cases and controls. This conforms to the findings of Rocha et al. [41] who reported that 156 (75.0\%) of their study subjects were females while validating the WHOQOL-BREF in depressed Brazilians.

A similar result was presented by Yun-San et al. [27] while studying the QOL in elderly depressed patients in Taiwan. The predominance of females in this study is consistent with the World Health Organization's (WHO) epidemiological results indicating that more women suffer from depression than men. Another reason for the female predominance could be explained by the fact that, most of the female participants were housewives and more likely to be found at home during the interview, unlike the male participants who were either at work or out of the house with friends. The males were also found to have alcohol and substance use problems thus excluding them from the study. Other possible explanations include; the cyclical fluctuation of female hormones which intensifies the physical stress-response that may amplify vulnerability to depression. Social factors present the world over also result in certain features being more typical of women's experience than men's, thus predisposing them to having a higher rate of depression. These include the greater likelihood of experiencing sexual and physical abuse, stress of bringing children up, a greater dependence and higher emotional reliance on social support, along with an increased willingness to report symptoms of current and past episodes of depression to physicians. In addition, poor education, including poor health education resulting in a lack of awareness, as well as orthodox customs, compounds the situation of women. Men tend to suppress their feelings and may perceive the need for assistance for emotional problems as a sign of weakness making it difficult to detect depression in men.

Although a sizeable number of the study subjects were married, a majority of them were single. The reason for the lower number of married subjects was not surprising because of the young age of the study population. The mean age of the participants was $39.11 \pm 12.40$ years. This is similar to what was found by Rocha et al. [41] where the mean age was $39.12 \pm 13.6$ years while validating the WHOQOL-BREF among depressed patients in Brazil. Another reason for the characteristic young age of the study population is because it is a common phenomenon in developing countries including Nigeria.

A majority of the study subjects had secondary education while less than a third had acquired tertiary education. Eighteen percent had no formal education as $15.5 \%$ only, had attained primary education. This conforms to the findings of Afolabi et al. [42]. They found that most of the subjects they studied had one form of tertiary education (36.0\%) or the other, $21.6 \%$ had no formal education while $21.2 \%$ had primary and secondary education each. In addition, the high rate of lack of education should be expected among the study subjects due to the 
fact that many children do not attend school because their labor is needed to either help at home or to bring additional income into the family. Many families cannot afford the associated costs of sending their children to school such as uniforms and textbooks. For others, the distance to the nearest school is a major hindrance. Another cause of low enrolment, especially in the North, is cultural bias. Most parents do not send their children, especially girls, to school and prefer to marry them out as teenagers.

About three-quarters of the subjects were employed while a quarter were however, not employed at the time of this study. A significant proportion of those employed $(81.0 \%)$ were in the control group while those employed among the cases constituted less than two-thirds. Agbir et al. [43] in their study to determine the prevalence of depression among medical outpatients with diabetes in Jos also reported a similar result where they found that majority of their subjects were employed while a quarter of them were not. The low employment level among the cases should be expected because of the discrimination and stigma which lead to job losses or outright refusal to employ individuals who have mental illness even if they are the most qualified for the job. This low employment status leads to lack of financial independence which is known to improve self-esteem and reduce stress.

Most of the subjects who had jobs earned less than 50 dollars $(<\mathrm{N} 2000.00$ Naira) per month (Table 1), a little over a quarter of them (26.5\%) earned between 50 - 125 dollars (i.e. 20,000.00 - 50,000.00 Naira), and only a small fraction (1.5\%) earned above 125 dollars per month. Fifty seven (28.5\%) had no form of income. The result obtained in this study also showed that cases tend to earn less income than the controls $(P<0.002)$. This could be due to the fact that most of the cases were down the occupational ladder, either due to job losses or due to the reason that majority of them engaged in menial jobs and petty trading from which the income is usually meager. Depression has also been shown to reduce productivity and increases absenteeism from work [44]. Only the controls earned above 125 dollars per month, thus, giving them more economic and social advantage in comparison to the cases.

\subsection{Comparison of Domain Scores}

In considering the results of this study on Table 4, there was a statistically significant relationship between the four domains of QOL and depression. A comparative analysis of the mean scores revealed that depressed respondents scored lower than the control group which is indicative of poorer QOL. The result also showed a negative association between the four domains and depressive disorders. This means that depression had significantly lowered QOL in the respective domains. The outcomes here were consistent with those of previous studies [27] [28] [34] [45].

The physical domain which assesses areas such as energy and fatigue, pain and discomfort, and sleep and rest was impaired among the cases as they scored poorer on the WHOQOL-BREF. This can be explained by the fact that depression 
as an illness impacts negatively on energy levels, sleep and comfort. Previous studies [19] [46] reported a similar outcome.

On the psychological domain, the depressed respondents (cases) rated their QOL to be worse than the control group as evidence by their lower mean score. The reason for this could be adduced to the fact that depression as a clinical entity is almost always associated with negative self perception and negative cognition. The finding here is supported by studies [7] [8] [46] carried out by other researchers in the past.

The depressed respondents in this study also fared poorly on the physical domain when compared to the controls. This could be due to the strained interpersonal relationships, poor social support, loss of interest in pleasure and negative cognition that is common among depressed individuals. The poor relationship can also explain the poor sexual function among the cases when compared to the control group. In separate studies conducted by Dew et al. [9] and Lynn Chung et al. [17] among depressed patients in Taiwan using the WHOQOLBREF, intensity of depressive symptoms and social isolation were reported to have the greatest direct effect on all four QOL domains

The environmental domain measures financial resources, freedom, physical safety and security, health and social care: accessibility and quality, home environment, opportunities for acquiring new information and skills, participation in and opportunities for recreation/leisure, physical environment (pollution/ noise/traffic/climate) and transport. This study was able to demonstrate that patients who suffer from depressive illness are more likely to report a decrease in their satisfaction in the above mentioned areas. One thing that could have impacted negatively on this domain is the increasing security challenges and worry for safety among the patients who are usually vulnerable or abandoned during the repeated crises the state is experiencing now.

\section{Conclusions}

This study shows that depression significantly affects the QOL of patients. The overall subjective QOL as well as the physical, psychological, social and environmental domains of the patients was shown to be poorer when compared to that of the control population. The study also revealed that patients who suffer from depression experience marked reduction in global functioning when compared with non depressed population.

Finally, depression just as it has been reported in previous is shown to interfere with the fulfillment of goals, roles and dreams in this study. Practitioners are therefore expected to screen for and develop treatment programs aimed at improving depressive symptoms. This will ultimately improve the QOL of patients with depression.

\section{Strength and Limitation of the Study}

Nigeria is a very large country with important cultural differences among its 
regions. This study was carried out in North Central zone of the country. Thus, it cannot be considered as being representative of the diversity that occurs in the country. Nevertheless, it is relevant due to the fact that it highlights the importance of early diagnosis and appropriate treatment for depression.

\section{References}

[1] The WHOQOL Group (1998) Development of the World Health Organization (WHOQOL-BREF) Quality of Life Assessment. Psycho Medicine, 28, 551-558. https://doi.org/10.1017/S0033291798006667

[2] The WHOQOL Group (1995) The World Health Organization Quality of Life Assessment (WHOQOL): Position Paper from the World Health Organization. Social Science Medicine, 10, 1403-1409.

[3] Blazer, D.G. (1995) Mood Disorders: Epidemiology. In: Kaplan, H.I. and Sadock, B.J., Eds., Comprehensive Text Book of Psychiatry, 6th Edition, William and Wilkins, Philadelphia, 1079-1088.

[4] Weich, S., Morgan, L., King, M. and Nazareth, I. (2007) Attitudes to Depression and Its Treatment in Primary Care. Psycho Medicine, 37, 1239-1248. https://doi.org/10.1017/S0033291707000931

[5] Murray, C.J. and Lopez, A.D. (1997) Global Mortality, Disability and Contribution of Risk Factors: Global Burden of Disease Study. Lancet, 17, 1436-1442. https://doi.org/10.1016/S0140-6736(96)07495-8

[6] World Health Organization (2013) World Health Report. WHO, Geneva.

[7] McQuaid, J.R., Stein, M.B., Laffaye, C. and McCahill, M.E. (1999) Depression in a Primary Care Clinic: Prevalence and Impact of an Unrecognized Disorder. Journal of Affective Disorders, 55, 1-10. https://doi.org/10.1016/S0165-0327(98)00191-8

[8] Angermeyer, M.C. and Matschinger, H. (1997) Social Distance towards the Mentally Ill: Results of Representative Surveys in Federal Republic of Germany. Psycho Medicine, 27, 131-141. https://doi.org/10.1017/S0033291796004205

[9] Dew, M.A., Bromet, E.J., Schulberg, H.C., Parkinson, D.K. and Curtis, E.C. (1991) Factors Affecting Service Utilization for Depression in a White Collar Population. Social Psychiatry and Psychiatric Epidemiology, 26, 230-237. https://doi.org/10.1007/BF00788971

[10] Ayuso-Mateos, J.L., Vasquez-Barquero, J.L., Dowrick, C., Lehtonen, J., Dalgard, O.S. and Casey, P. (2001) Depressive Disorders in Europe: Prevalence Figures from the ODIN Study. British Journal of Psychiatry, 1979, 308-316. https://doi.org/10.1192/bjp.179.4.308

[11] Kuehner, C. (2002) Subjective Quality of Life: Validity Issues with Depressed Patients. Acta Psychiatrica Scandinavica, 106, 62-70. https://doi.org/10.1034/j.1600-0447.2002.02204.x

[12] Ravindran, A.V., Matheson, K., Griffiths, J., Merali, Z. and Anisman, H. (2002) Stress, Coping and Uplifts and Quality of Life in Subtypes of Depression: A Conceptual Frame and Emerging Data. Journal of Affective Disorders, 71, 121-130. https://doi.org/10.1016/S0165-0327(01)00389-5

[13] Blazer, D.G., Kesler, R.C., McGonagle, K.A. and Swartz, M.S. (1994) The Prevalence and Distribution of Major Depression in a National Community Sample: The National Comorbidity Survey. American Journal of Psychiatry, 151, 979-986. https://doi.org/10.1176/ajp.151.7.979 
[14] Bland, R.C. (1997) Epidemiology of Affective Disorders: A Review. The Canadian Journal of Psychiatry, 42, 367-377. https://doi.org/10.1177/070674379704200403

[15] Angermeyer, M.C., Holzinger, A., Matschinger, H. and Strengler-Wenzke, K. (2002) Depression and Quality of Life: Results of Follow-Up Study. International Journal of Psychiatry, 48, 189-199. https://doi.org/10.1177/002076402128783235

[16] Kennedy, S.H., Einsfield, B.S. and Cooke, R.G. (2001) Quality of Life: An Important Assessment in the Treatment of Depression. Journal of Psychiatry \& Neuroscience, 26, 523-528.

[17] Chung, L., Pan, A. and Hsiung, P.C. (2009) Quality of Life for Patients with Major Depression in Taiwan: A Model-Based Study of Predictive Factors. Psychiatry Research, 168, 153-162. https://doi.org/10.1016/j.psychres.2008.04.003

[18] Eaton, W.W., Regier, D.A., Locke, B.Z. and Taube, C.A. (1981) The Epidemiologic Catchments Area Program of the National Institute of Mental Health. Public Health Reports, 96, 319-325.

[19] Judd, L.L., Paulus, M.P., Wells, K.B. and Rapaport, M.H. (1996) Socioeconomic Burden of Subsyndromal Depressive Symptoms and Major Depression in a Sample of the General Population. American Journal of Psychiatry, 153, 1411-1417. https://doi.org/10.1176/ajp.153.11.1411

[20] Johnson, J., Weissman, M.M. and Klerman, G.L. (1992) Service Utilization and Social Morbidity Associated with Depressive Symptoms in the Community. JAMA, 267, 478-483. https://doi.org/10.1001/jama.1992.03480110054033

[21] Weissman, M.M., Prusoff, B.A., Thompson, W.D., Harding, P.S. and Myers, J.K. (1978) Social Adjustment by Self-Report in a Community Sample and in Psychiatric Outpatients. Journal of Nervous and Mental Disease, 166, 317-326. https://doi.org/10.1097/00005053-197805000-00002

[22] Cummins, A.R. (2000) Objective and Subjective Quality of Life: An Interactive Model. Social Indicators Research, 52, 55-72. https://doi.org/10.1023/A:1007027822521

[23] Yen, C.F., Tsai, J.J., Lu, P.L., et al. (2004) Quality of Life and Its Correlates in HIV/AIDS Male Outpatients Receiving Highly Active Antiretroviral Therapy in Taiwan. Psychiatry and Clinical Neurosciences, 58, 501-506. https://doi.org/10.1111/j.1440-1819.2004.01292.x

[24] Simon, E.S. (2003) Social and Economic Burden of Mood Disorders. Biological Psychiatry, 54, 208-215. https://doi.org/10.1016/S0006-3223(03)00420-7

[25] Trompenaars, F.J., Masthoff, E.D., Van Heck, G.L., Hodiamont, P.P. and De Vries, J. (2006) Relationship between Mood-Related Disorders and Quality of Life in Population of Dutch Adult Psychiatric Outpatients. Depression and Anxiety, 23, 353363. https://doi.org/10.1002/da.20180

[26] da Silva, L. and de Almeida, F.M.P. (2007) Sub-Syndromal Depression: An Impact on Quality of Life? Journal of Affective Disorders, 100, 163-169. https://doi.org/10.1016/j.jad.2006.10.010

[27] Chang, Y.-S., Liang, S.-C., Chen, M. and Lu, M. (2006) Quality of Life in Elderly with Depressive Disorders. Taiwan Geriatrics \& Gerontology, 2, 21-31.

[28] Yen, C., Chen, C., Lee, Y., Tang, T., Hundg, C. and Yen, Y. (2009) Association between Quality of Life and Self-Stigma, Insight and Effects of Medication in Patients with Depressive Disorders. Depression and Anxiety, 26, 1033-1039. https://doi.org/10.1002/da.20413 
[29] Zeng, Q., Xu, Y. and Wang, W. (2013) Quality of Life of Patients with Depression in China. Journal of Affective Disorders, 150, 513-521. https://doi.org/10.1016/j.jad.2013.04.052

[30] Goldney, R.D., Fisher, L.J., Wilson, D.H. and Cheok, F. (2000) Major Depression and Its Associated Morbidity and Quality of Life in a Random, Representative Australian Community Sample. Australian and New Zealand Journal of Psychiatry, 34, 1022-1029. https://doi.org/10.1080/000486700279

[31] Karl, P. and Nancy, P. (2013) Depression and Associated Factors in Older Adults in South Africa. Global Health Action, 6, 18871.

https://doi.org/10.3402/gha.v6i0.18871

[32] Esam, M.A., Mohammed, A.I., Mohammed, T. and Yasser, E. (2014) Assessment of Health-Related Quality of Life, Anxiety and Depression in Patients with Early Rheumatoid Arthritis. The Egyptian Rheumatologist, 36, 51-56. https://doi.org/10.1016/j.ejr.2013.12.004

[33] Adewuya, A.O. and Makanjuola, R.O. (2009) Subjective Quality of Life of Nigerian Schizophrenia Patients: Socio-Demographic and Clinical Correlates. Acta Psychiatrica Scandinavica, 120, 160-164. https://doi.org/10.1111/j.1600-0447.2009.01395.x

[34] Gureje, O., Kola, L. and Afolabi, E. (2007) Epidemiology of Major Depressive Disorder in Elderly Nigerians in the Ibadan Study of Ageing: A Community-Based Survey. The Lancet, 370, 957-964. https://doi.org/10.1016/S0140-6736(07)61446-9

[35] Bawo, O.J., Olufemi, M., George, O.E., Ambrose, O.L. and Joyce, O.O. (2010) Depression and Subjective Quality of Life among Outpatients with Diabetes Mellitus at a Teaching Hospital in Nigeria. Mental Health in Family Medicine, 7, 179-183.

[36] WHO Global Burden of Disease (2008) 2004 Update. World Health Organization, Geneva.

http://www.who.int/healthinfo/global_burden_disease/GBD_report_2004update_fu $\underline{11 . p d f}$

[37] Well, K.B., Golding, J.M. and Burnam, M.A. (1988) Psychiatric Disorder in a Sample of the General Population with and without Chronic Medical Conditions. American Journal of Psychiatry, 145, 967-981.

[38] WHOQOL Group (1998) The WHO Quality of Life Assessment (WHOQOL): Development and General Psychometric Properties. Social Science \& Medicine, 46, 1569-1583. https://doi.org/10.1016/S0277-9536(98)00009-4

[39] Sheehan, D.V., Lecruibier, Y. and Harnett-Sheehan, K. (1998) The Mini International Neuropsychiatric Interview. The Journal of Clinical Psychiatry, 59, 22-33.

[40] National Bureau of Statistics (2008) Federal Republic of Nigeria: Nigeria Demographic and Health Survey. National Bureau of Statistics, Nigeria.

[41] Rocha, N.S. and Fleck, M.P. (2009) Validity of the Brazilian Version of WHOQOLBREF in Depressed Patients Using Rasch Modeling. Revista de Saúde Pública, 43, 147-153. https://doi.org/10.1590/S0034-89102009000100019

[42] Afolabi, M.O., Abioye-Kuteyi, E.A., Fatoye, F.O., Bello, I.S. and Adewuya, A.O. (2008) Pattern of Depression among Patients in Nigerian Family Practice Population. SA Fam Pract, 50, 63. https://doi.org/10.1080/20786204.2008.10873701

[43] Agbir, T.M. (2010) Depression among Medical Outpatients with Diabetes: A Cross-Sectional Study at Jos University Teaching Hospital, Jos, Nigeria. Annals of African Medicine, 9, 5-10. https://doi.org/10.4103/1596-3519.62617

[44] Go'ar, G.S., Moses, D.A. and Michael, T.A. (2013) Sickness Absence among Depressed Patients Attending the General Out Patients Department of the Jos University Teaching Hospital, Jos, Nigeria. Nigerian Journal of Medicine, 15, 97-100. 
[45] Amini, H. and Sharifi, V. (2012) Quality of Life in Type I Bipolar Disorder in a One Year Follow-Up. Depression Research and Treatment, 2012, Article ID: 860745.

[46] Weng, Y.C., Cindy, L.K.L., Samuel, Y.S.W., Yvonne, Y.C.L., Daniel, Y.T.F., Tai, P.L., Peter, W.H.L., Josephine, W.S.W., Billy, C.F.C. and Kit, T.Y.C. (2011) The Epidemiology and Natural History of Depressive Disorders in Hong Kong's Primary Care. BMC Family Practice, 12, 129. https://doi.org/10.1186/1471-2296-12-129 